\section{Importance of 'Blue' Photon Levels for Lettuce Seedlings Grown under Red-light-emitting Diodes}

\author{
M.E. Hoenecke, R.J. Bula, and T.W. Tibbitts \\ Department of Horticulture, University of Wisconsin, Madison, WI 53706 \\ Additional index words. hypocotyls, elongation, cotyledons, light intensity, Lactuca \\ sativa
}

\begin{abstract}
Light-emitting diodes (LEDs) with high-intensity output are being studied as a photosynthetic light source for plants. High-output LEDs have peak emission at $\approx 660 \mathrm{~nm}$ concentrated in a waveband of $\pm 30 \mathrm{~nm}$. Lettuce (Lactuca sativa 'Grand Rapids') seedlings developed extended hypocotyls and elongated cotyledons when grown under these LEDs as a sole source of irradiance. This extension and elongation was prevented when the red LED radiation was supplemented with more than $15 \mu \mathrm{mol} \cdot \mathrm{m}^{-2} \cdot \mathrm{s}^{-1}$ of 400- to 500-nm photons from blue fluorescent lamps. Blue radiation effects were independent of the photon level of the red radiation.
\end{abstract}

Light-emitting diodes (LEDs) have been proposed as a photosynthetic radiation source for space flight growing systems and as a more efficient source for terrestrial controlled-environment agriculture facilities (Bula et al., 1991). We have observed that lettuce and other dicotyledonous plants develop excessive hypocotyl elongation when grown under high-intensity red-emitting LEDs as the sole source of irradiance.

Radiant energy in the blue portion of the visible spectrum suppresses hypocotyl and

\footnotetext{
Received for publication 3 July 1991. Accepted for publication 4 Feb. 1992. Supported by the College of Agricultural and Life Sciences and the College of Engineering. Univ. of Wisconsin-Madison and the National Aeronautics and Space Administration grant NAG-W975. The cost of publishing this paper was defrayed in part by the payment of page charges. Under postal regulations, this paper therefore must be hereby marked advertisement solely to indicate this fact.
}

stem growth of plants (Sale and Vince, 1959; Wassink and Stolwijk, 1956). To suppress hypocotyl elongation in lettuce 10 $\mu \mathrm{mol} \cdot \mathrm{m}^{-2} \cdot \mathrm{s}^{-1}$ of blue photons are required, and in tomato (Lycopersicon esculentum Mill.) and cucumbers (Cucumis sativus L.), a greater photon flux is required (Thomas and Dickinson, 1979). In Sinapis, $30 \mu \mathrm{mol} \cdot \mathrm{m}^{-2} \cdot \mathrm{s}^{-1}$ of blue photons $(\approx 20 \mathrm{~nm}$ half-band width at $446 \mathrm{~nm}$ ) effectively inhibited elongation of hypocotyls (Holmes and Schafer, 1981). Further, as little as $10^{-4} \mu \mathrm{mol} \cdot \mathrm{m}^{-2} \cdot \mathrm{s}^{-1}$ of 446-nm photons had an inhibiting effect on hypocotyl elongation of Sinapis in the absence of other photosynthetic radiation. Hypocotyl elongation of Sinapis alba L. (white mustard), Spinacia oleracea L., and Latuca sativa L. were inversely correlated with the $\log$ of the blue-photon flux between 17 and $151 \mu \mathrm{mol} \cdot \mathrm{m}^{-2} \cdot \mathrm{s}^{-1}$ (Tibbitts et al., 1983). In addition, the effects of blue wavelengths on hypocotyl elongation were independent of the flux of other photons and, thus, not related to the quantity of photosynthetic or total photons.

Less is known about the effect of blue photons on the extension of cotyledons and leaves than on the extension of hypocotyls. To our knowledge, no study has included the effects of blue wavelengths on cotyledon development at levels of photosynthetic radiation that would support normal growth of plants. Investigations with low levels of blue light on Sinapis (Bergs et al., 1983) or Pisum sativum L. (Elliott, 1975) indicate that the only response to low levels of blue wavelengths was an increase in leaf length.

The purpose of this study was to determine the blue-photon flux required for normal seedling development of lettuce when grown under red radiation provided by LEDs. Seedling response was studied at two photosynthetic photon levels to determine if seedlings respond to a specific flux of blue photons or to a percentage of the total photosynthetic photon flux. Measurements were made of hypocotyl elongation and cotyledon expansion.

Experiments were conducted in a controlled-environment room of the Univ. of Wisconsin Biotron. The room was fitted with specific radiation sources to provide the desired irradiation levels. A sufficient number of red-radiation-emitting LEDs were used to provide desired amounts of total photosynthetic irradiation over a $13 \times 15-\mathrm{cm}$ area.

The LEDs used were fabricated with a gallium-aluminum-arsenide chip that had a peak emission of $660 \mathrm{~nm}$ (Fig. 1), as determined with a LI-COR spectroradiometer (LICOR, Lincoln, Neb.). The LEDs were mounted on a transparent polycarbonate board ( $2 \mathrm{~mm}$ thick) in an array of 72 lamps (nine $x$ eight rows). The distance between centers of individual diodes was $15 \mathrm{~mm}$. Alternate rows were off-set $7.5 \mathrm{~mm}$ to provide more uniform irradiance. The LED arrays were powered with a DC power supply that allowed for adjusting the current to the LEDs 

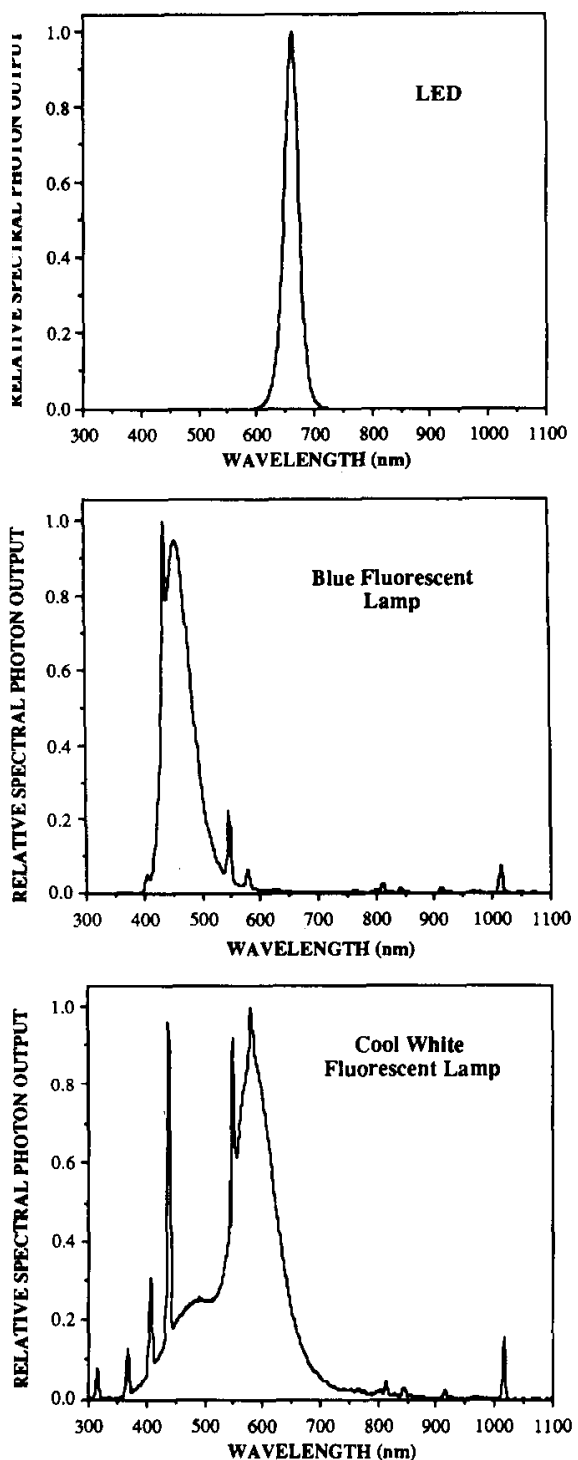

Fig. 1. Relative photon output from radiation sources.

to obtain the desired photon flux.

Blue photons were obtained from F20 T12/ 246 blue fluorescent lamps (Sylvania, Danvers, Mass.). This blue-photon source was used instead of blue LEDs, since no blue LEDs of adequate intensity have been developed. The fluorescent tubes had peak emission between 435 and $470 \mathrm{~nm}$ (Fig. 1). Two blue fluorescent tubes were mounted directly above the LED arrays, separated by $0.5 \mathrm{~cm}$, to roughly equal the width of the LED array. The transparent LED mounting plate allowed the blue photons to be effectively distributed with the red photons onto the plant-growing surface. The sections of the blue fluorescent bulbs that were not directly above the LED arrays were covered with aluminum foil to avoid greater side irradiation of the seedlings than that provided with the LEDs.

A "white light" control (Fig. 1) from two very high-output cool-white fluorescent lamps (Sylvania) was also installed in the room. The sections of the tubes that were not above the germination surface were covered with

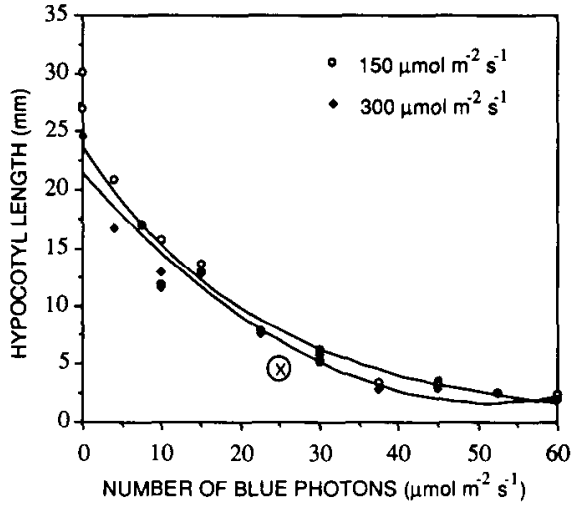

Fig. 2. Relationship between lettuce seedling hypocotyl length and flux of blue photons at two photosynthetic photon flux levels provided by red LEDs and blue fluorescent lamps. $\otimes$, Cool-white fluorescent lamp control. Each point represents an average value for six to 10 seedlings measured in each experiment, except $\otimes$ $=$ average for 48 seedlings measured in five experiments. Regression equation for $150 \mathrm{PPF}$ : $\mathrm{Y}=23.791 \times 10^{-0.0193 x}, R^{2}=0.965 ; 300$ PPF: $Y=20.026 \times 10^{-0.0176 x}, R^{2}=0.962$.

aluminum foil. The LED plus blue fluorescent and cool-white fluorescent lighting systems were set up in the same chamber to ensure uniformity in temperature and humidity. The systems were separated by a black cloth to isolate radiation output of the different lighting systems.

'Grand Rapids' lettuce seed from a single seed lot was selected, and to ensure uniformity in seedling vigor, light and heavy seeds were removed. The seeds were placed on moistened black polyester fabric supported by gray PVC plates. The PVC plates had two parallel slits $(0.7 \mathrm{~cm}$ wide $)$ in the center $\approx 1.5$ $\mathrm{cm}$ apart. The polyester fabric, cut to size, was inserted through these slits. The PVC plates were placed on top of 1-liter black rectangular plastic containers filled with nutrient solution (Hammer et al., 1978). The fabric acted as a wick to draw the solution up to the seeds. Ten seeds were arranged $\approx 0.5 \mathrm{~cm}$ apart along each of the outside edges of the slit. After $24 \mathrm{~h}$ six uniform seedlings in each slit were selected for use and carefully repositioned along the slit edges $\approx 1 \mathrm{~cm}$ apart. The remaining seedlings were discarded. In the first four experiments, only 12 seeds were placed on the germinating surface and six to 10 uniform seedlings were selected for use.

The average air temperature and relative humidity at the top of the plants were 20.0 $\pm 0.5 \mathrm{C}$ and $70 \% \pm 3 \%$, respectively, as measured with a wet and dry bulb thermocouple psychrometer. The seeds and leaves were at $20.0 \pm 0.5 \mathrm{C}$, as measured with a fine-wire thermocouple. Photon measurements were made with a LI-COR Model Li185 quantum sensor with cosine-corrected filter. There was no measurable change in photon level during the course of each study, nor between repeated experiments at similar photon levels. Irradiation was continuous.

Two levels of photosynthetic photon flux (PPF) $\left(150\right.$ and $\left.300 \mu \mathrm{mol} \cdot \mathrm{m}^{-2} \cdot \mathrm{s}^{-1}\right)$ were used

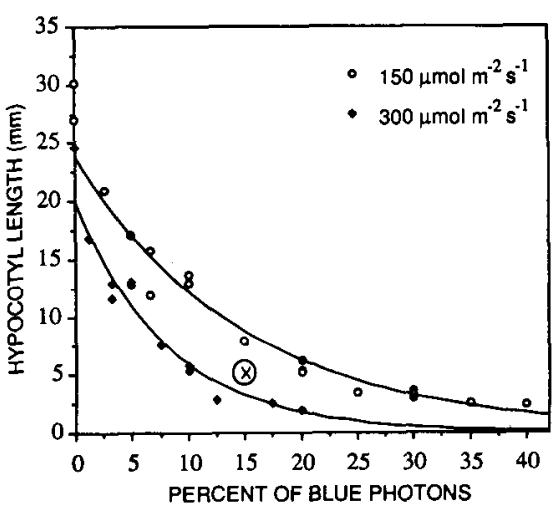

Fig. 3. Relationship between lettuce seedling hypocotyl length and the percentage of blue photons at two photosynthetic photon flux levels provided by red LEDs and blue fluorescent lamps. $\bigotimes$, Cool-white fluorescent lamp control. Each point represents an average value for six to 10 seedlings measured in each experiment, except $\otimes=$ average for 48 seedlings measured in five experiments. Regression equation for 150 PPF: $\mathrm{Y}=23.812 \times 10^{-0.0289 x}, R^{2}$ $=0.965 ; 300$ PPF: $\mathrm{Y}=19.984 \times 10^{0.0527 \mathrm{x}}$, $R^{2}=0.962$.

in the studies. The blue irradiance treatments were $60,52.5,45,37.5,30,22.5,15,10$, $7.5,4$, and $0 \mu \mathrm{mol} \cdot \mathrm{m}^{-2} \cdot \mathrm{s}^{-1}$. The red-photon flux was adjusted at each blue-photon flux level to provide a total PPF of 150 and 300 $\mu \mathrm{mol} \cdot \mathrm{m}^{-2} \cdot \mathrm{s}^{-1}$ (Table 1$)$. Seedlings were maintained at varying distances from the LED arrays for the different treatments, ranging from 1 to $12 \mathrm{~cm}$, depending on the selected blue-photon level.

Seedling hypocotyl length and cotyledon length and width were measured following 6 days of growth. The largest and smallest seedlings (determined by cotyledon length and width) in each treatment were discarded. The data represent an average of six to 10 plants for each blue photon level experiment. Certain photon levels were repeated two or three times and separate data values produced for each replication. A total of 18 data points were obtained at $150 \mu \mathrm{mol} \cdot \mathrm{m}^{-2} \cdot \mathrm{s}^{-1}$ and 15 at $300 \mu \mathrm{mol} \cdot \mathrm{m}^{-2} \cdot \mathrm{s}^{-1}$. A fitted curve of the data points was generated using an exponential equation for hypocotyl lengths and quadratic polynomial equation for cotyledon length and width.

\section{Hypocotyl elongation}

Elongation of the hypocotyl was significantly affected by the incident blue-photon flux level. As seedlings were exposed to increasing flux of blue photons from 0 to 60 $\mu \mathrm{mol} \cdot \mathrm{m}^{-2} \cdot \mathrm{s}^{-1}$, hypocotyl elongation decreased from 30 to $2 \mathrm{~mm}$ (Fig. 2). More than half of this decrease in hypocotyl elongation occurred at a blue photon flux between 0 and $15 \mu \mathrm{mol} \cdot \mathrm{m}^{-2} \cdot \mathrm{s}^{-1}$. Very little hypocotyl elongation was noted when the seedlings were grown under blue-photon flux levels $\geq 30$ $\mu \mathrm{mol} \cdot \mathrm{m}^{-2} \cdot \mathrm{s}^{-1}$. Under normal field and greenhouse environments, lettuce plants develop a hypocotyl between 5 and $15 \mathrm{~mm}$ long, this elongation was produced by $\approx 30$ and $10 \mu \mathrm{mol} \cdot \mathrm{m}^{-2} \cdot \mathrm{s}^{-1}$ in this study. 


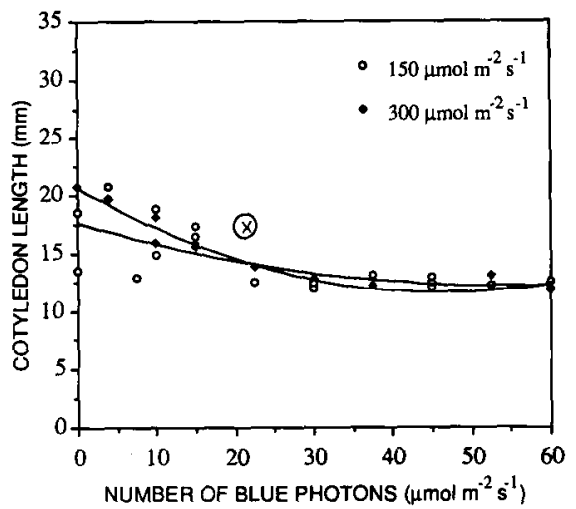

Fig. 4. Relationship between lettuce seedling cotyledon length and blue-photon flux at two photosynthetic photon flux levels provided by red LEDs and blue fluorescent lamps. $\otimes$, Coolwhite fluorescent lamp control. Each point represents an average value for six to 10 seedlings measured in each experiment, except $\otimes=$ average for 48 seedlings measured in five experiments. Regression equation for 150 PPF: $\mathrm{Y}=$ $6.226+0.0210 \mathrm{X}-0.00016 \mathrm{X}^{2}, R^{2}=0.096$; 300 PPF: $\mathrm{Y}=7.916-0.0704 \mathrm{X}+0.00121 \mathrm{X}^{2}$, $R^{2}=0.803$

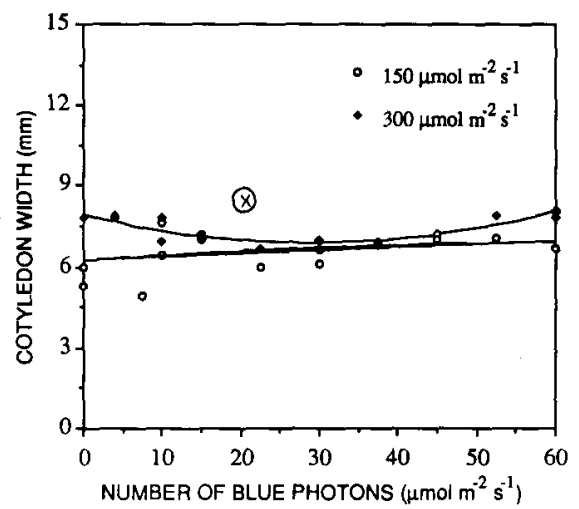

Fig. 5. Relationship between lettuce seedling cotyledon width and blue-photon flux for two photosynthetic photon flux levels provided by red LEDs and blue fluorescent lamps. $\otimes$, Coolwhite fluorescent lamp control. Each point represents an average value for six to 10 seedlings measured in each experiment, except $\otimes=$ average for 48 seedlings measured in five experiments. Regression equation for 150 PPF: $\mathrm{Y}=$ $17.665-0.2068 \mathrm{X}+0.00194 \mathrm{X}^{2}, R^{2}=0.487$ 300 PPF: $Y=20.717-0.3955 X+$ $0.00424 X^{2}, R^{2}=0.953$.

Table 1. Photon flux in various spectral regions provided by the various lamps used to irradiate lettuce seedlings, as determined with a LI-COR spectroradiometer.

\begin{tabular}{|c|c|c|c|}
\hline \multirow[b]{2}{*}{ Lamp type } & \multicolumn{3}{|c|}{ Spectral region $(\mathrm{nm})$} \\
\hline & $400-500$ & $500-600$ & $600-700$ \\
\hline \multicolumn{4}{|c|}{ Photosynthetic photon flux $\left(\mu \mathrm{mol} \cdot \mathrm{m}^{-2} \cdot \mathrm{s}^{-1}\right)^{z}$} \\
\hline \multicolumn{4}{|c|}{$\begin{array}{l}\text { Red LEDs }+ \\
\text { blue fluorescent lamps } \\
\text { Total } 300\end{array}$} \\
\hline & $60.0(20.0)$ & $\ldots$ & $240.0(80.0)$ \\
\hline & $52.5(17.5)$ & $-\cdots$ & $247.5(82.5)$ \\
\hline & $37.5(12.5)$ & $\cdots$ & $262.5 \quad(87.5)$ \\
\hline & $30.0(10.0)$ & -- & $270.0(90.0)$ \\
\hline & $22.5(7.5)$ & -- & $277.5 \quad(92.5)$ \\
\hline & $15.0(5.0)$ & -.- & $285.0(95.0)$ \\
\hline & $10.0(3.3)$ & --- & $290.0(96.7)$ \\
\hline & $7.5(2.5)$ & -.- & $292.5 \quad(97.5)$ \\
\hline & $4.0(1.3)$ & $\cdots$ & $296.0(98.7)$ \\
\hline & $0.0(0.0)$ & $-\infty$ & $300.0(100.0)$ \\
\hline \multicolumn{4}{|c|}{ Total 150} \\
\hline & $60.0(40.0)$ & $\cdots$ & $90.0 \quad(60.0)$ \\
\hline & $52.5(35.0)$ & $\cdots$ & $97.5(65.0)$ \\
\hline & $45.0(30.0)$ & -.- & $105.0(70.0)$ \\
\hline & $37.5(25.0)$ & -.- & $112.5(75.0)$ \\
\hline & $30.0(20.0)$ & $-\infty$ & $120.0(80.0)$ \\
\hline & $22.5(15.0)$ & -- & $127.0(85.0)$ \\
\hline & $15.0(10.0)$ & -- & $135.0(90.0)$ \\
\hline & $10.0(6.7)$ & -- & $140.0(93.3)$ \\
\hline & $7.5(5.0)$ & $\ldots$ & $142.5(95.0)$ \\
\hline & $4.0 \quad(2.7)$ & $\cdots$ & 146.0 (97.3) \\
\hline & $0.0 \quad(0.0)$ & $\cdots$ & $150.0(100.0)$ \\
\hline \multirow{2}{*}{\multicolumn{4}{|c|}{$\begin{array}{l}\text { Cool-white } \\
\text { fluorescent lamps }\end{array}$}} \\
\hline & \multicolumn{3}{|c|}{ fluorescent lamps } \\
\hline & & & \\
\hline & $24.0(16.0)$ & $105.0(70.0)$ & $(14.0)$ \\
\hline
\end{tabular}

${ }^{2}$ Percentage of total photosynthetic photon flux in parentheses.

The flux of blue photons required for control of hypocotyl elongation in this study was independent of the PPF level, since the curvilinear hypocotyl elongation response was statistically similar $(P=0.05)$ under PPF of 150 and $300 \mu \mathrm{mo} 1 \cdot \mathrm{m}^{-2} \cdot \mathrm{s}^{-1}$ (Fig. 2). This blue photon flux requirement can be illustrated by plotting hypocotyl length against the percentage of photons that were of blue wavelengths (Fig. 3). Two separate curves are evident; one at each of the two PPF levels, indicating that the quantity of incident blue photons, rather than the percentage of incident blue photons, is the critical factor affecting hypocotyl growth. This result supports earlier evidence (Thomas and Dickin- son, 1979; Tibbitts et al., 1983) that lettuce seedlings respond to a specific number of blue photons rather than a blue : total PPF ratio.

The average hypocotyl length of seedlings developing under cool-white fluorescent lamps was $4.1 \mathrm{~mm}$ (Fig. 2). This lamp system provided $24 \mu \mathrm{mol} \cdot \mathrm{m}^{-2} \cdot \mathrm{s}^{-1}$ of 400 - to $500-\mathrm{nm}$ (blue) photons. A similar amount of hypocotyl elongation was obtained with blue photon levels of $\approx 35 \mu \mathrm{mol} \cdot \mathrm{m}^{-2} \cdot \mathrm{s}^{-1}$ in treatments using blue fluorescent lamps and red LEDs. Thus, the spectrum of blue photons from the cool-white fluorescent lamps appears to have been more effective in inhibiting hypocotyl elongation than the spectrum of blue photons provided by the blue fluorescent lamps. The particular wavelengths provided by the coolwhite and blue fluorescent lamps were different (Fig. 1) and these differences could have had different effects on the blue-absorbing active pigment. Also, the greater amount of ultraviolet radiation emitted by the cool-white fluorescent source may have produced some inhibitory activity that resulted in more hypocotyl inhibition. If the blue-absorbing pigment is a flavoprotein that can absorb radiation in the UV region of the spectrum, as suggested by Briggs and Lino (1983) and Schmidt (1984), then the greater inhibitory action of the cool-white fluorescent source could be due to the greater amount of UV radiation emitted by this fluorescent lamp. The possibility cannot be ignored that the cool-white fluorescent source, with emissions in the red and infrared regions, may have activated phytochrome; thus, this pigment may have had an interacting effect on elongation.

There was no evidence that the level of red photons regulated hypocotyl elongation. Hacker et al. (1964) reported "opposing" affects on elongation of lettuce hypocotyls subjected to red photon treatments at germination. They observed growth in certain regions of the hypocotyl being promoted by red light, and in other regions being suppressed. Specific regions of the hypocotyl were not measured in this study to determine if this balancing effect occurred.

\section{Cotyledon expansion}

Cotyledon size and shape were related to the blue-photon flux incident on the seedlings. As the blue-photon flux increased from 0 to $30 \mu \mathrm{mol} \cdot \mathrm{m}^{-2} \cdot \mathrm{s}^{-1}$, cotyledon length decreased from 20 to $13 \mathrm{~mm}$ (Fig. 4). Increasing the level of blue photons in excess of 30 $\mu \mathrm{mol} \cdot \mathrm{m}^{-2} \cdot \mathrm{s}^{-1}$ had no additional measurable effect on cotyledon development. The effects of blue-photon flux levels on cotyledon extension may be manifested via the cotyledon petiole. The petiole, like the hypocotyl, elongates as low levels of blue photons. This elongation gives the cotyledon a strapshaped appearance. With decreasing bluephoton flux levels, the lower part of the blade fails to develop, increasing the strap-like appearance to the cotyledon. This pattern is similar to that reported in another study in which the leaf sheath at the base of the blade 
of Lolium multiflorum Lam. elongated with decreasing amounts of blue photons (Casal and Alvarez, 1988).

Similar decreases in cotyledon length were noted at both PPF levels, suggesting that the blue light response was independent of the incident PPF. The blue fluorescent lamps produced greater inhibition of cotyledon length than the cool-white fluorescent lamps (Fig. 4).

In contrast, cotyledon width appeared not to be related to the blue-photon flux level (Fig. 5). The cotyledon width was between 6.0 and $8.0 \mathrm{~mm}$ at all levels of incident blue photons. There was an indication that cotyledon width was controlled some by the PPF level, with slightly greater width at increased PPF levels. Cotyledon width of seedlings developing under cool-white fluorescent lamps was $1.0 \mathrm{~mm}$ wider (9.0 $\mathrm{mm}$ in width) than that of seedlings grown with red LEDs and different levels of blue photons. This result suggests that the broader spectrum of coolwhite fluorescent lamps may have promoted wider cotyledons.

This investigation demonstrates that blue photons are required to minimize elongation of hypocotyls and petioles of lettuce seedlings and likely also are required for any plants that develop with extended hypocotyls, stems, and petioles. A certain amount of elongation is desirable and, therefore, a blue-photon flux level between 15 and $30 \mu \mathrm{mol} \cdot \mathrm{m}^{-2} \cdot \mathrm{s}^{-1}$ for $12 \mathrm{~h}$ each day would be an acceptable level for lettuce growth. Additional studies are needed to determine required levels of blue photons for other species.

Presently available blue LEDs have very low output and cannot provide the required blue-photon flux. However, small fluorescent lamps that emit blue light can be obtained and could be installed within an array of red LEDs to provide a satisfactory LED lighting source for plants. Considerable commercial interest is directed toward improving blue LEDs and, therefore, these may be available in the near future.

\section{Literature Cited}

Beggs, C.J., J. Barth, and E. Schafer. 1983. The effect of light on cotyledon and primary leaf growth in white light grown Sinapis alba. Physiol. Plant. 57:114-118.

Briggs, W.W. and M. Lino. 1983. Blue-light-absorbing photoreceptors in plants. Philosophical Trans. Royal Soc. London Ser. B 303:347-359.

Bula, R.J., R.C. Morrow, T.W. Tibbitts, R.W. Ignatius, T.S. Martin, and D.J. Barta. 1991. Light emitting diodes as a radiation source for plants. HortScience 26(2):203-205.

Casal, J.J. and M.A. Alvarez. 1988. Blue light effects on the growth of Lolium multiflorum Lam. leaves under natural radiation. New Phytol. 109:41-45

Elliott, W.M. 1975. Light-controlled leaf expansion in peas grown under different light conditions. Plant Physiol. 55:717-719.

Hacker, M., K.M. Hartmann, and H. Mohr. 1964. Zellteilung und Zellwachstum im Hypokotyl von Lactuca sativa L. unter dem Einfluss des Lichtes. Planta 63:253-268.

Hammer, P.A., T.W. Tibbitts, R.W. Langhans, and J.C. McFarlane. 1978. Base-line growth studies of 'Grand Rapids' lettuce in controlled environments. J. Amer. Soc. Hort. Sci. 103:649655.

Holmes, M.G. and E. Schafer. 1981. Action spectra for changes in the "high irradiance reaction" in hypocotyls of Sinapis alba L. Planta 153:267-272.

Sale. P.J.M. and D. Vince. 1959. Effects of wavelength and time of irradiation on internode length in Pisum sativum and Tropaeolum majus. Nature (London) 183:1174-1175.

Schmidt, W. 1984. Bluelight physiology. BioScience 34:698-704.
Thomas, B. and H.G. Dickinson. 1979. Evidence for two photoreceptors controlling growth in deetiolated seedlings. Planta 146:545-550.

Tibbitts, T.W., D.C. Morgan, and I.J. Warrington. 1983. Growth of lettuce, spinach, mustard, and wheat plants under four combinations of high-pressure sodium, metal halide, and tungsten halogen lamps at equal PPFD. J. Amer. Soc. Hort. Sci. 168:622-630.

Wassink, E.C. and J.A.J. Stolwijk. 1956. Effects of light quality on plant growth, p. 373-400. In: L.R. Blinks (ed.) Annual review plant physiology. vol. 7. 